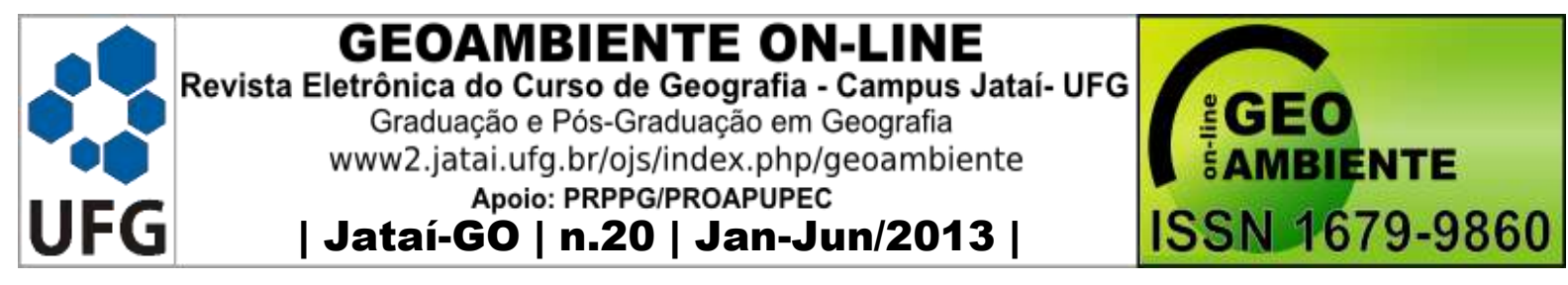

\title{
DOENÇAS DE VEICULAÇÃO HÍDRICA: DADOS EPIDEMIOLÓGICOS, CONDIÇÕES DE ABASTECIMENTO E ARMAZENAMENTO DA ÁGUA EM MASSARANDUBA/PB
}

Antonio Cardoso Silva Filho, Rafael Dantas de Morais, Janaina Barbosa da Silva

(Universidade Federal de Campina Grande; tonycardoso.geo@hotmail.com;

rafaeldantas.m@hotmail.com; janainasimov@yahoo.com)

\section{Resumo}

A nuança primordial no que se refere à qualidade e suficiência dos recursos hídricos para o abastecimento humano é a proteção, manutenção e promoção da saúde em suas variadas dimensões. Neste contexto, considera-se que o município que não dispõe de sistemas de abastecimento de água regular e de qualidade, apresenta uma maior vulnerabilidade a condições de risco a saúde. Assim, o objetivo deste trabalho foi analisar a incidência e prevalência de doenças por meio de veiculação hídrica com as condições de abastecimento e armazenamento da água no município de Massaranduba/PB. Para viabilizar a pesquisa, considerando os aspectos teóricos e práticos da realidade, optou-se pelos seguintes procedimentos: a) delimitação da área de estudo; b) trabalho de campo e c) obtenção dos resultados. Constatou-se que as formas específicas de abastecimento (açude; chuva; poço; compra) e armazenamento (caixa de água; cisterna; tonel) no Município remete a uma situação epidemiológica agravante no que tange a proliferação das doenças de veiculação hídrica, principalmente, as diarréicas e a dengue. Neste viés observou-se o reconhecimento desta conjuntura por parte da população local, uma vez que sofrem reflexos na saúde decorrente desta condição socioambiental de vulnerabilidade e risco. Portanto, as doenças de veiculação hídrica apresentaram relações com as condições de abastecimento e armazenamento da água no contexto investigado.

Palavras Chaves: Fatores de risco ambiental; determinantes sociais; saúde coletiva.

\section{Abstract}

\footnotetext{
Artigo recebido para publicação em 29 de Novembro de 2012
}

Artigo aprovado para publicação em 15 de Maio de 2013 


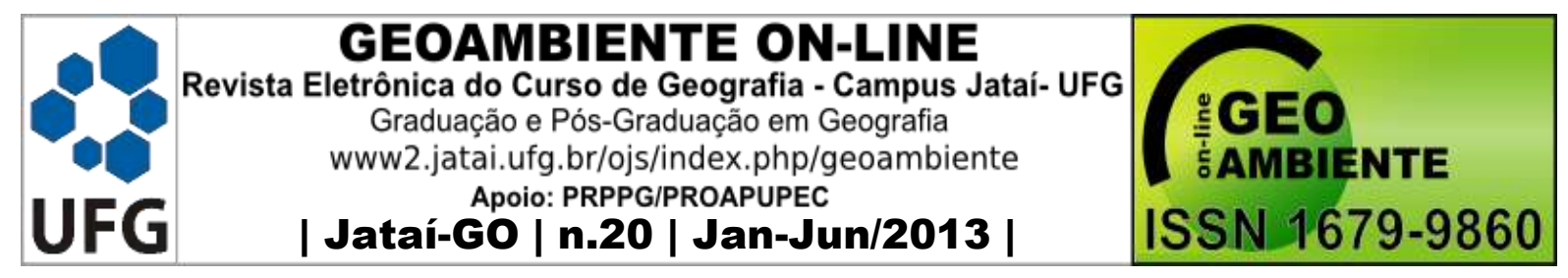

\section{WATERBORNE DISEASES: EPIDEMIOLOGIC DATA, CONDITIONS OF SUPPLY AND STORAGE OF WATER IN MASSARANDUBA - BRAZIL}

The nuance paramount with regard to the quality and sufficiency of water resources for human supply is the protection, maintenance and promotion of health in its various dimensions. In this context, it is the municipality that does not have water supply systems and regular quality has a greater vulnerability to risk health conditions. The objective of this study was to analyze the incidence and prevalence of diseases through waterborne with the conditions of supply and storage of water in the municipality of Massaranduba / PB. To facilitate the research, considering the theoretical and practical aspects of reality, we opted for the following: a) demarcation of the study area, b) fieldwork c) obtaining results. It was found that the specific forms of supply (dam; rain; well; purchase) and storage (water box, tank, vat) in the city refers to an aggravating epidemiological situation regarding the proliferation of waterborne diseases, especially the diarrhea and dengue. This bias was observed recognition of this situation by the local population, since suffering the health consequences resulting from this environmental condition of vulnerability and risk. Therefore, waterborne diseases had relations with the conditions of supply and storage of water in the investigated context.

Keywords: environmental risk factors, social determinants, health collective.

\section{Resumen}

\section{ENFERMEDADES TRANSMITIDAS POR EL AGUA: LOS DATOS EPIDEMIOLÓGICOS, CONDICIONES DE SUMINISTRO Y ALMACENAMIENTO DE AGUA EN MASSARANDUBA - BRASIL}

El matiz de suma importancia en lo que respecta a la calidad y suficiencia de recursos hídricos para el abastecimiento humano es la protección, el mantenimiento y la promoción de la salud en sus diversas dimensiones. En este contexto, es el municipio que no cuentan con sistemas de abastecimiento de agua y la calidad normal tiene una mayor vulnerabilidad al riesgo de problemas de salud. El objetivo de este estudio fue analizar la incidencia y prevalencia de enfermedades transmitidas por el agua a través de las condiciones de suministro y almacenamiento de agua en el municipio de Massaranduba / PB. Para facilitar la investigación, teniendo en cuenta los aspectos teóricos y prácticos de la realidad, nos decidimos por el siguiente: a) delimitación de la zona de estudio, b) trabajo de campo c) la obtención de resultados. Se encontró que las formas específicas de la oferta (la presa, la 


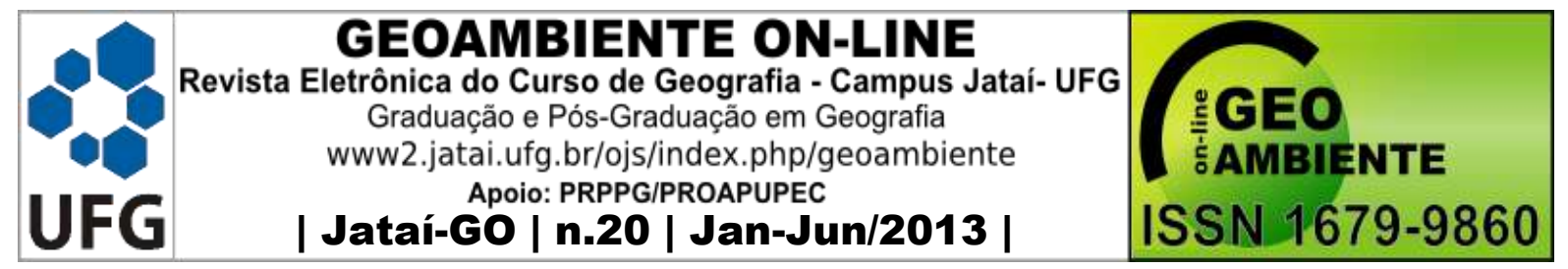

lluvia, así, la compra) y de almacenamiento (caja de agua, tanque, tanque) de la ciudad se refiere a la situación epidemiológica agravante con respecto a la proliferación de enfermedades transmitidas por el agua, especialmente la diarrea y el dengue. Este sesgo se observó el reconocimiento de la situación de la población local, desde que sufrió las consecuencias para la salud derivadas de esta condición ambiental de la vulnerabilidad y el riesgo. Por lo tanto, las enfermedades transmitidas por el agua tenían relaciones con las condiciones de suministro y almacenamiento de agua en el contexto investigado.

Palabras clave: Factores de riesgo ambietales; determinantes sociales; salud colectiva

\section{Introdução}

A distribuição e armazenamento da água como um condicionante e determinante das condições de saúde da população é objeto de discussão de vários estudiosos (d'AGUILA, et al., 2000; FREITAS et al., 2001; AMARAL, et al., 2003). Sob as investigações em torno desta perspectiva incidem discussões que se relacionam as mudanças sutis da saúde, uma vez que esta é marcada por fatores socioambientais, dentre eles, as condições de consumo da água.

De acordo com Amaral et al., (2003) as doenças de veiculação hídrica, são causadas principalmente por meio de microrganismos patogênicos que têm suas origens relacionadas aos fatores espaciais do território e, são situações específicas são determinadas pelos preceitos capitalistas e dicotômicos que regem a sociedade, assumindo relevância, entre outros aspectos, na determinação de desigualdades no que tange a qualidade da água para consumo e uso humano. Assim, as doenças de veiculação hídrica nas dimensões de incidência e prevalência causam inúmeros transtornos à saúde humana, sendo esta percebida em seu contexto patológico, social e espacial como o conjunto de fatores (materiais e imateriais) que podem interferir negativamente nas condições gerais de existência.

De acordo com d'Aguila et al., (2000) os principais recursos hídricos em termos de sistemas de distribuição, estão associados a reservatórios e redes desenvolvidas para suprir as necessidades quando não há suficiência de sistemas naturais, como por exemplo, mananciais, rios etc. Nesta perspectiva, a manutenção e qualidade da água tanto de sistemas de distribuição, quanto de sistemas naturais são fundamentais para a qualidade de vida populacional mantida por esses recursos. Deste modo, alguns dos fatores que podem comprometer a qualidade da água, e consequentemente da saúde, indicados por Freitas et. al. 


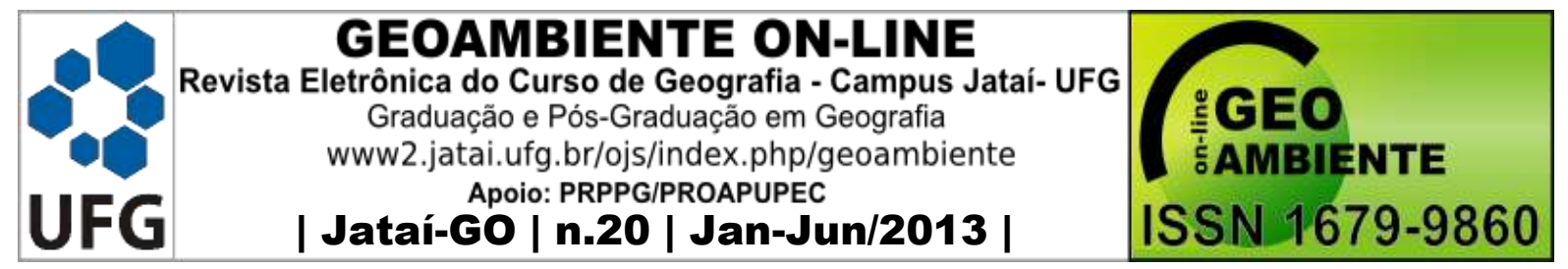

(2001), associa-se a qualidade química e biológica da fonte natural e a eficácia do processo de tratamento e armazenamento.

Neste sentindo, essa problemática evidenciada pelos avanços e retrocessos do sistema de produção espacial, assim como por determinantes naturais (climáticos), atinge diversos municípios brasileiros, sendo efetivado no Brasil como um dos serviços básicos com menor cobertura estatal (PNAD, 2004). Diante desta situação, buscam-se explicações voltadas aos fatores responsáveis por estas condições, definidas por Evans (1997) como uma situação etiológica.

Partindo desses pressupostos, para o desenvolvimento de sistemas de água com suficiente qualidade demanda-se de outros sistemas mais amplos que considerem a necessária melhoria dos aparelhos de saneamento básico como um todo (NERE, 2010). Sendo assim, um município que não possui abastecimento de água por meio de recursos hídricos em suas especificidades de qualidade (tratamento) e quantidade (armazenamento) apresentam maior vulnerabilidade ao risco de doenças.

Neste viés, de acordo com Amaral et al.,(2003) a captação de água em localidades sem os recursos necessários expostos a várias fontes de contaminação, aumenta consideravelmente o risco a determinados agravos ou surtos de doenças nestas localidades. Logo, análises que ultrapassam o campo patológico da doença podem contribuir para progressão de políticas públicas consistentes no âmbito possibilista de combate à falta de água e ao tratamento desta, uma vez que em situação de negligência, este recurso natural pode transportar doenças que refletem na população e, portanto, no perfil do território e da paisagem.

Nos casos em que o município necessita desenvolver práticas voltadas ao abastecimento de água em suas conotações individuais ou coletivas, o risco que a água pode oferecer assume variações, dependendo quase que exclusivamente do conhecimento que determinados sujeitos possuem nos processos inerentes a estas ações.

Desta forma, evidencia-se o papel social destas discussões, uma vez que se trata de análises que desenvolvem olhares multilaterais voltados à melhoria das condições gerais de existência da população, atentando-se a progressiva multidisciplinaridade presente nas dinâmicas da complexidade do real e cada vez mais nos campos teóricos da comunidade cientifica.

Esta pesquisa foi desenvolvida objetivando compreender as doenças ocasionadas pela água. Inicialmente, buscou-se estabelecer critérios para a identificação do município da 


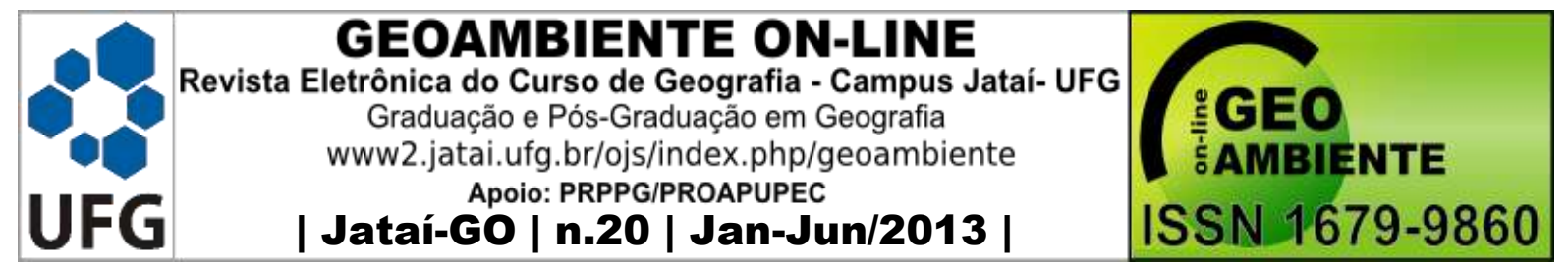

microrregião de Campina Grande que apresenta menor disponibilidade hídrica, uma vez que este seria o mais necessitado quanto ao desenvolvimento de práticas de armazenamento de água. Identificar o tipo de acesso, armazenamento e a qualidade desta água e as possíveis doenças. Essa última corroborando dados da Secretaria Municipal de Saúde com dados coletados através de questionários com os moradores pesquisados. Outro objetivo foi escolher o município que apresentasse o menor índice pluviométrico.

Para a identificação especifica dos municípios, consideraram-se os seguintes aspectos: existência de reservatórios monitorados no perímetro territorial da microrregião; redes de abastecimento regular de água advindos destes reservatórios; quantitativo de poços para capitação de água subterrânea; índice pluviométrico registrado no ano de 2012, onde todos os dados foram adquiridos na AESA (2012).

O desenvolvimento da pesquisa ocorreu entre os meses de março, abril e maio de 2012, quando ainda não há valores pluviométricos significativos e várias formas de abastecimento são disponibilizadas: carro-pipa, captação em açudes, barreiros, compra, abastecimento oficial através da CAGEPA entre outros

Descrição da área de estudo: A microrregião de Campina Grande e as condições de uso e abastecimento de água

Atentou-se para o desenvolvimento de análises dos contextos territoriais, demográficos e ambientais do estado da Paraíba, especificamente da microrregião de Campina Grande, uma vez que esta, além de demonstrar relevância no cenário socioeconômico da Paraíba, possui dinâmicas diferenciadas quanto à existência de recursos hídricos, climáticos e de abastecimento no decorrer de sua divisão territorial.

A microrregião de Campina Grande (Figura 01) é composta pelos municípios de Boa Vista, Campina Grande, Fagundes, Lagoa Seca, Massaranduba, Puxinanã, Queimadas e Serra Redonda. De acordo com dados do Instituto Brasileiro de Geografia e Estatística (IBGE, 2010) esta microrregião possui uma totalidade de 502.669 habitantes, em uma unidade territorial de 2.103,65 km².

No que se refere às condições ambientais desta microrregião, sobretudo dos recursos hídricos, observa-se que o abastecimento, quando existente, advém de um único reservatório com monitoramento da Agência Executiva de Gestão das Águas do Estado da Paraíba (AESA, 2012) (Açude Epitácio Pessoa/Boqueirão). De modo que o monitoramento dos 


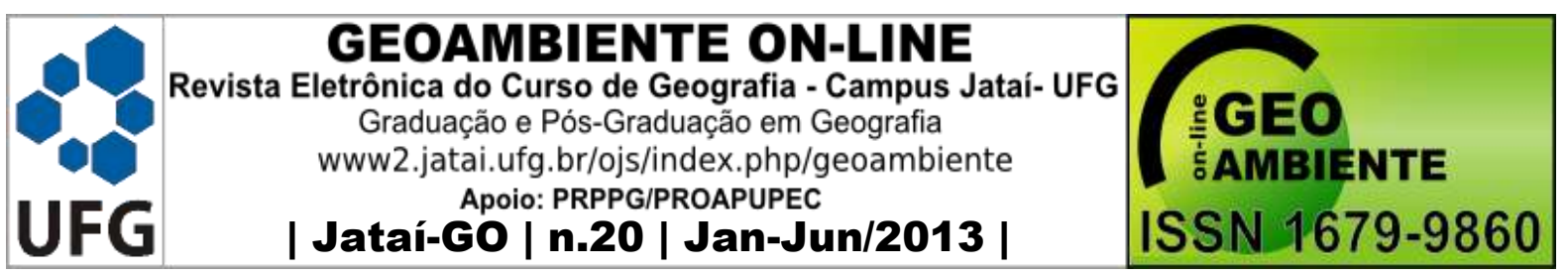

reservatórios distribuídos no Estado assume importância substancial no controle de qualidade da água e conseqüentemente nas condições sanitárias que reflete e é reflexo do perfil epidemiológico de determinada localidade (AESA, 2012). Daí surge alguns questionamentos, como por exemplo, qual o município da área de estudo que apresenta menor disponibilidade hídrica decorrente da baixa pluviosidade natural, limitando a disponibilidade natural através de açudes, rios, barreiros e etc. Quais os principais reservatórios de água dessas localidades e as implicações na saúde humana? De modo que essas discussões serão norteadoras da investigação que segue.

Figura 01: Mapa da microrregião de Campina Grande -PB

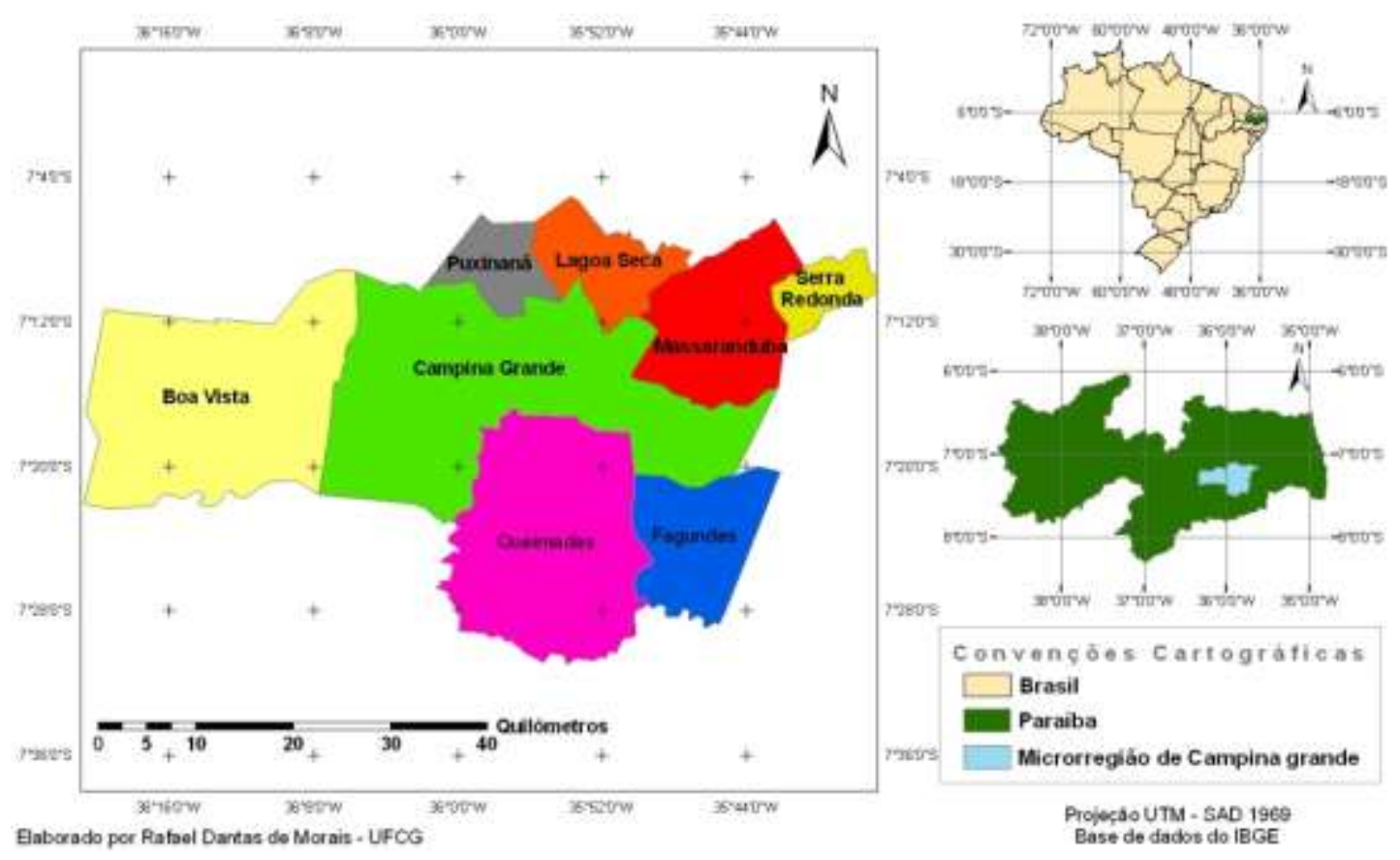

\section{Metodologia}

Para viabilizar a pesquisa, considerando os aspectos teóricos e práticos da realidade, optou-se pelos seguintes procedimentos: a) delimitação da área de estudo; b) obtenção dos dados de campo; c) análise dos resultados.

\section{Delimitação da área de estudo}

Após identificar o município com menor índice pluviométrico, buscou-se identificar a situação dos reservatórios monitorados pela AESA, constatou-se a inexistência destes 


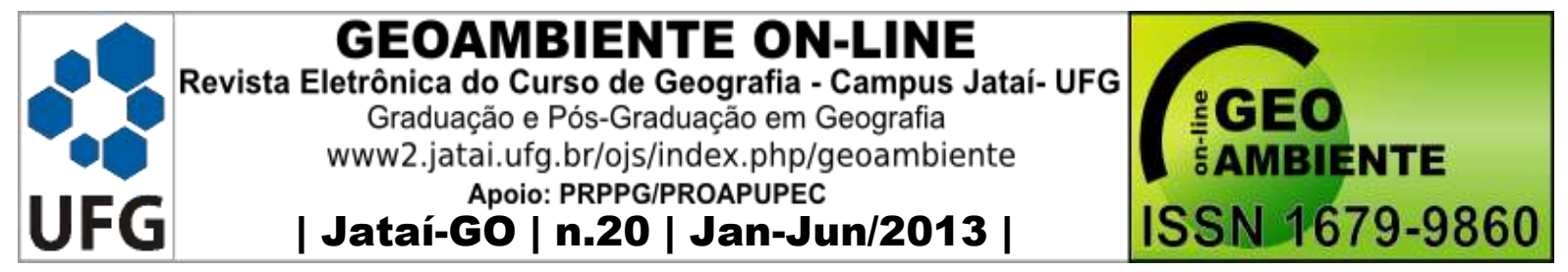

recursos no perímetro territorial correspondente à microrregião. Assim, todos os municípios são dependentes do sistema de redes de abastecimento ligados aos reservatórios condizentes com a qualidade garantida pela AESA.

Diante desta situação, foi necessário avaliar se todos os municípios da microrregião apresentam sistemas ou projetos de abastecimento regular de água. Logo, de acordo com a Agência Nacional de Águas (ANA, 2010), as redes de fornecimento provenientes dos açudes monitorados pela AESA, vinculadas a organismos públicos e privados da microrregião, atendem as cidades de Boa Vista, Campina Grande, Puxinanã, Queimadas e Fagundes. Sendo assim, as cidades de Lagoa Seca, Massaranduba e Serra Redonda estão inseridas no contexto básico de acesso a água apenas através dos serviços da Companhia de Água e Esgotos Paraíba (CAGEPA).

Buscando definir dentre os Municípios pré-selecionados (Lagoa Seca, Massaranduba e Serra Redonda) qual teria o maior déficit de abastecimento, verificou-se o quantitativo de poços para capitação de água subterrânea. Segundo dados do IBGE (2010) Massaranduba e Serra Redonda apresentaram a menor incidência destas fontes alternativas de acumulo e abastecimento de água (um poço público para cada cidade).

Atentando-se ao objetivo proposto, a cidade mais indicada para a realização do trabalho de campo foi Massaranduba por apresentar, além dos fatores supracitados, o menor índice pluviométrico no ano de $2012(431 \mathrm{~mm})$ em relação à cidade de Lagoa Seca $(697 \mathrm{~mm})$.

\section{Obtenção dos dados de campo}

O trabalho de campo foi efetivado através, inicialmente, de coletas de dados na Secretaria de Saúde do município de Massaranduba, especificamente no setor de vigilância epidemiológica. Em seguida, foram aplicados questionários em residências localizadas na malha urbana do Município. Atentou-se para o desenvolvimento e adequação de critérios que considerassem tanto a complexidade do real, quanto o teor e rigorosidade científica necessários em um trabalho de natureza acadêmica.

Desta forma, foram solicitados da vigilância epidemiológica, dados referentes ao quantitativo de casos confirmados de dengue; hepatite tipo A; cólera e verminoses (esquistossomose, ascaridíase, teníase, oxiuríase, ancilostomíase) dos anos de 2010, 2011 e 2012. Essas enfermidades específicas foram consideradas nesta análise como as mais comuns doenças de veiculação hídricas ligadas ao armazenamento e abastecimento de água 


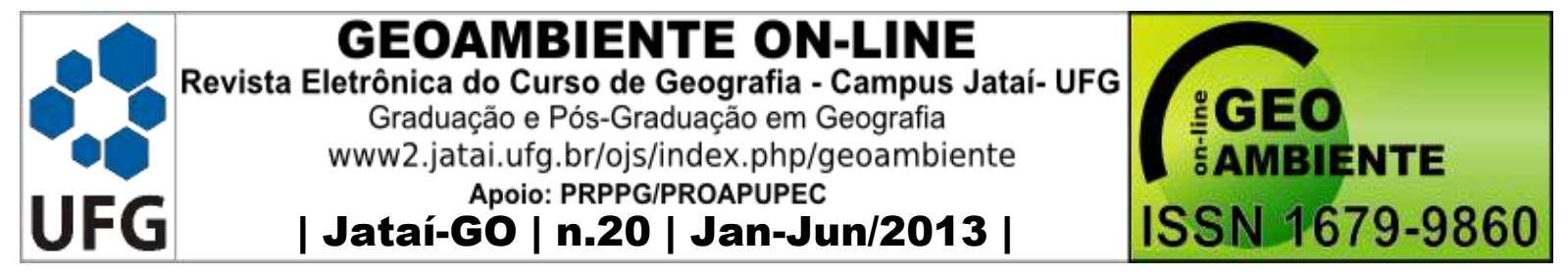

(FERREIRA \& SILVEIRA, 2004; AGUILA, et al., 2000; FERREIRA et al., 2008; GIATTI et al., 2004; BARCELLOS et al., 2005). Outro aspecto inerente à escolha destas doenças relaciona-se ao fato de abarcarem tanto os condicionantes de risco relativos à ingestão ou contato direto com a água (hepatite tipo A, cólera e verminoses), quanto aos aspectos voltados unicamente ao acumulo deste recurso natural (dengue).

No que diz respeito aos questionários, desenvolvido com base nas indicações de Minayo (1998) e adaptado ao objetivo da pesquisa, utilizou-se de técnicas de cartografia digital (ArcGis 10 licenciado para o Laboratório de Cartografia Digital, Geoprocessamento e Sensoriamento Remoto-CADIGEOS dos cursos de pós-graduação do Centro de Humanidades da Universidade Federal de Campina Grande-UFCG), combinadas com métodos estatísticos (amostragem sistemática e amostragem aleatória simples) para sua aplicação. A amostragem sistemática viabilizou a escolha das quadras nas quais se aplicou os questionários através da divisão da totalidade do espaço amostral (65 quadras) pelo número de amostras definidas (20 quadras). Assim, obteve-se a razão (3) que norteou a delimitação das quadras selecionadas para o trabalho.

Por fim, a escolha do quantitativo de questionários aplicados correspondeu a seleção de três residências por quadra, as quais foram sorteadas através da utilização da amostragem aleatória simples totalizando 60 questionários.

\section{Análise dos resultados}

A análise dos resultados consistiu na organização, armazenamento e processamento dos dados e informações coletadas durante o trabalho de campo. Nesta perspectiva, houve o desenvolvimento de matrizes que evidenciam os dados e informações coletadas separadamente através do levantamento documental (vigilância epidemiológica) e aplicação dos questionários (residências).

Desta forma, observaram-se pontualmente as informações e o perfil referente tanto a situação de incidência de doenças de veiculação hídrica, quanto às condições de abastecimento e armazenamento da água que propiciam determinada situação epidemiológica. Logo, percebeu-se a necessidade de correlacionar e analisar tais situações.

\section{Resultados e discussão}




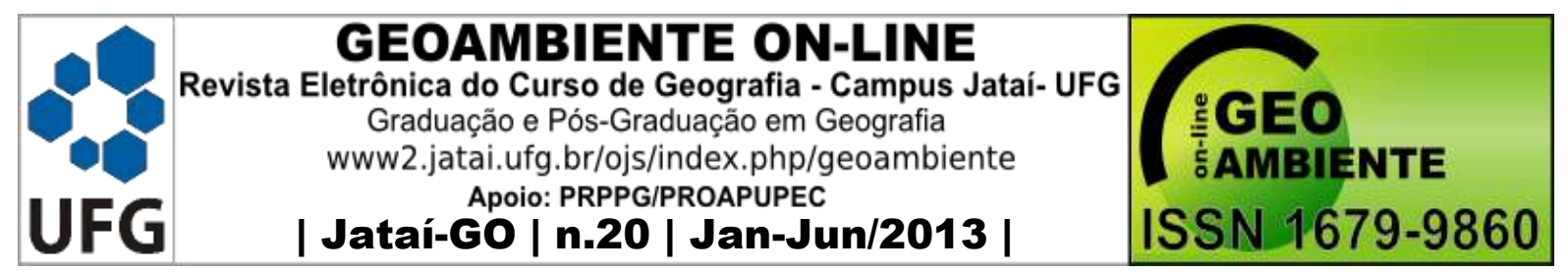

No intuito de estabelecer um parâmetro não disjuntivo e mais integrado dos fatores e objetos investigados em maior profundidade, observa-se que o município de Massaranduba apresentou uma situação consideravelmente extensa de casos registrados de algumas das doenças consideradas de veiculação hídrica no contexto investigado. Os dados coletados, no que tange a contabilização das doenças, são advindos de sistemas operacionais online dos quais a prefeitura se utiliza para fomentação e armazenamento dos dados epidemiológicos do Sistema de Informação de Agravos de Notificação (SINAN) e do Sistema de Informação da Vigilância Epidemiológica - Doenças diarreicas agudas (SIVEP-DDA).

Assim, constatou-se com relação a dengue, no espaço temporal investigado (2010/2011/2012), a incidência de 16 casos notificados. No que se refere aos casos de hepatite tipo A, observou-se a ocorrência de dois casos confirmados nos respectivos anos. Já no que se refere à cólera, não foi notificado nenhum caso. No que diz respeito às verminoses (esquistossomose, ascaridíase, teníase, oxiuríase, ancilostomíase) foram confirmados 1009 casos confirmados devido problemas diarréicos agudos (Tabela 01).

Tabela 01: Dados epidemiológicos coletados junto a Secretaria de Saúde do município de Massaranduba - PB

\begin{tabular}{c|c|c|c|c}
\hline \multirow{2}{*}{ Ano } & \multicolumn{3}{|c|}{ Doenças } & \multirow{2}{*}{ Total } \\
\cline { 2 - 4 } 2010 & Dengue & Hepatite A & Verminoses & 303 \\
2011 & 09 & 01 & 298 & 445 \\
2012 & 03 & 01 & 435 & 279 \\
\hline Total & 16 & 02 & 1009 & 1027 \\
\hline
\end{tabular}

Fonte: Secretaria Municipal de Saúde de Massaranduba -PB. (Organizado por Silva Filho \&

Morais 2012).

O ano de 2011 apresentou a maior notificação de doenças de veiculação hídrica em dimensão total (maior número correspondente à soma das diferentes doenças) e parcial (maior número individualizado de cada tipo de doença). Outro fator relativo à situação epidemiológica do Município se refere à alta taxa de casos de verminoses. De acordo com Giatti et al., (2004) estas doenças seriam as mais comuns em termos de percepção populacional quanto a veiculação hídrica, o que instiga ainda mais o pressuposto de correlação entre esse fator e as condições e variações da água. 


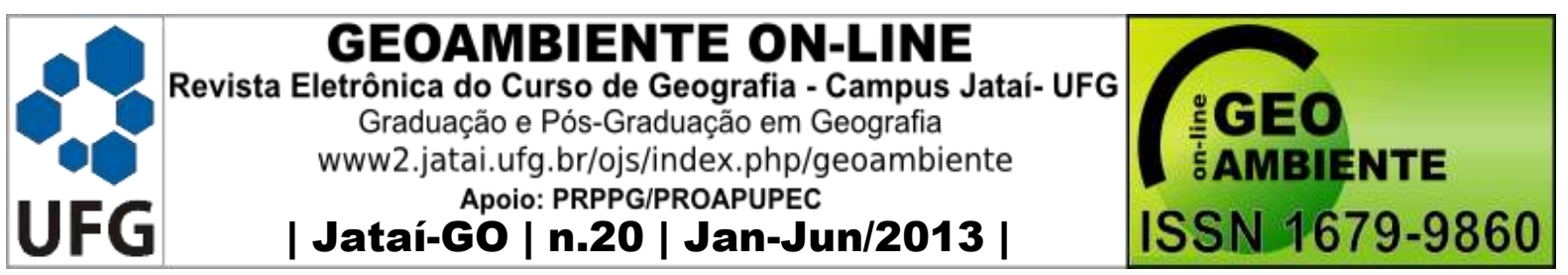

No que diz respeito ao levantamento empírico, constatou-se a relação entre a situação epidemiológica descrita com as principais formas de abastecimento e armazenamento de água por parte da população. Quanto especificamente ao espaço amostral (Massaranduba) observou-seque as formas de abastecimento e armazenamento assumem baixa variação no Município (Figura 02). Considerando a média quanto a estas especificidades por quadra.

Figura 02: Mapas do município de Massaranduba: Formas de abastecimento e armazenamento de água

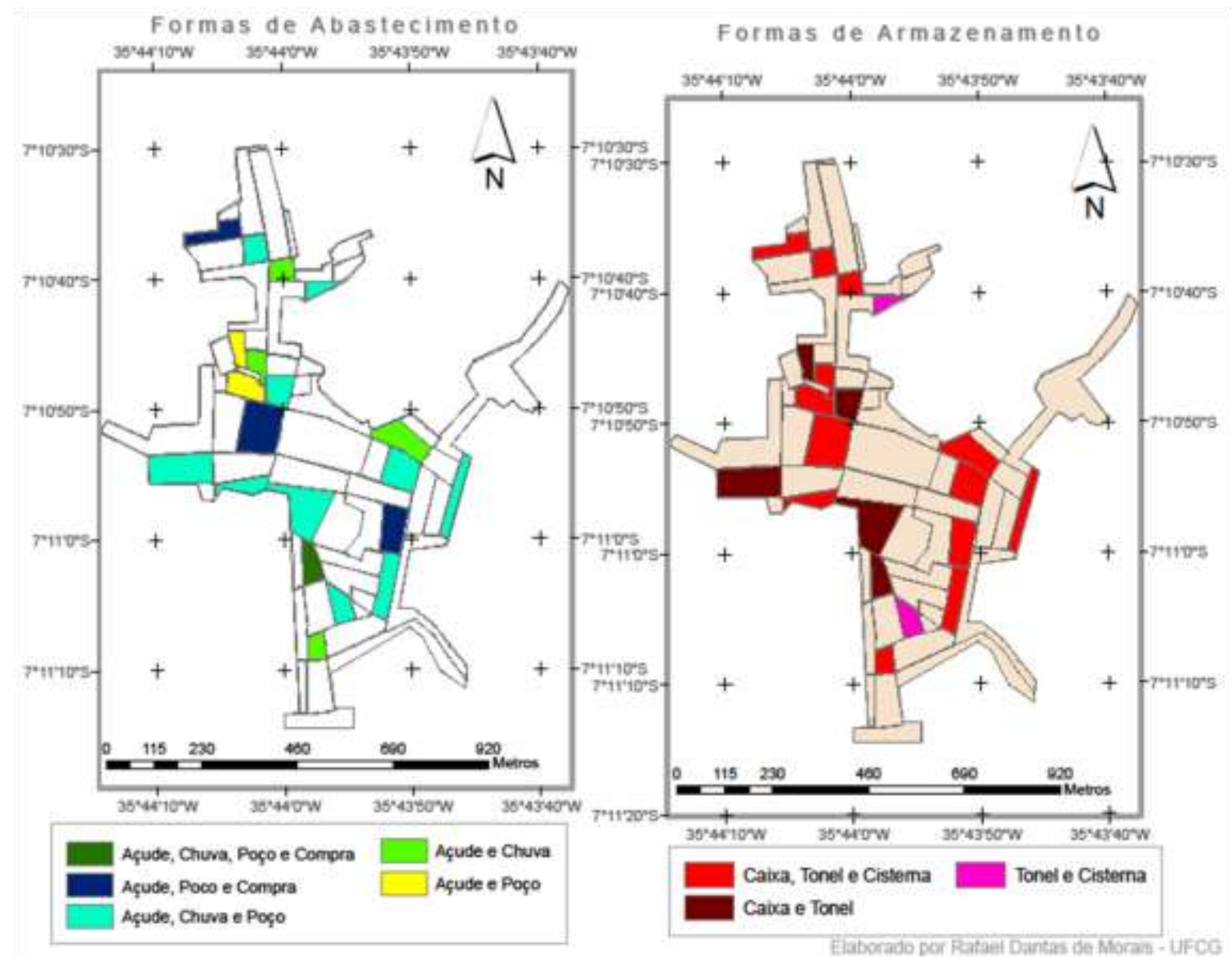

As formas de abastecimento no Município variaram entre: Capitação de água pelo açude Sindó Ribeiro; Captação de água de Poço artesiano; Capitação de água de chuva; Compra de água. Enquanto as formas de armazenamento alternaram-se entre: Caixa de água; tonel (nome popular a recipientes em formato cilíndrico de plástico ou ferro com capacidade de armazenar aproximadamente 200 litros de água); cisterna (no modelo adotado pelo governo federal). 


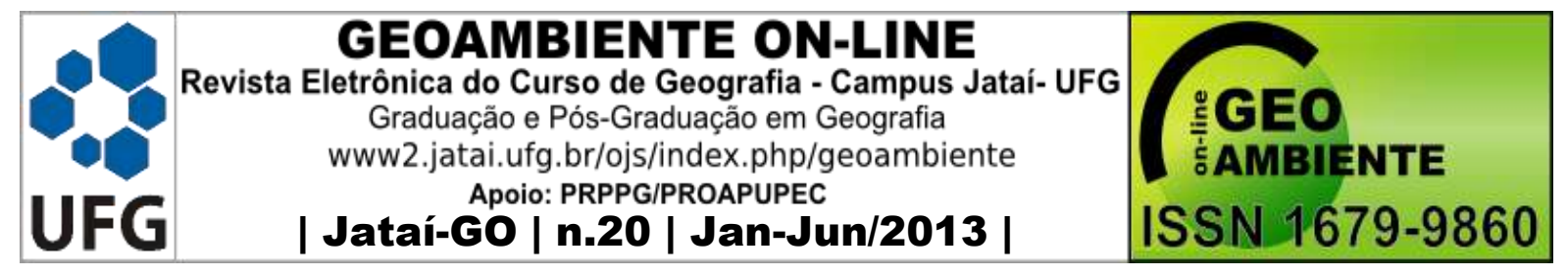

O abastecimento de água de acordo com a população está sendo viabilizado a partir de cinco combinações: açude, chuva, poço e compra; açude, poço e compra; açude, poço e chuva; açude e chuva; açude e poço. As formas de armazenamento variam entre três indicativos: caixa, tonel e cisterna; tonel e caixa, tonel e cisterna que por sua vez assumem relações autodependentes e autoexplicativas. Assim, chegou-se no seguinte modelo explicativo da relação entre o abastecimento e armazenamento constatado em campo.

Neste viés, ressalta-se que a relação existente entre as formas de abastecimento e armazenamento estende-se a determinações e influências destas características na saúde humana. O único modo de captação da rede de abastecimento residencial urbana é advindo do Açude Sindó Ribeiro monitorado pela CAGEPA. De acordo com a população entrevistada (questionários aplicados) a água advinda dessa rede de abastecimento na maioria das vezes apresenta alto teor de cloro, identificado pelos consumidores em função do forte odor e irritabilidade da pele refletindo assim na situação de doença.

Ainda no que tange a problemática do fornecimento de água, percebe-se que a totalidade dos moradores necessita de outras formas de abastecimento, considerando, sobretudo, a ineficácia quanto à distribuição deste recurso pela CAGEPA. Logo, o poço, a água da chuva e a compra de água foram alternativas outras verificadas segundo o discurso dos moradores.

Assim, a vulnerabilidade às situações que causem doenças específicas se torna abrangentes no sentido de facilitar a propensão ao risco por meio de contatos diretos ou ingestão da água proveniente da chuva, compra ou dos reservatórios localizados no perímetro territorial do Município, principalmente quando se considera as formas de armazenamento. As verminoses, que apresentaram o maior índice de incidência (1009 casos) nos anos avaliados (2010/2011/2012) podem ser indicadas como componentes incisivos desta situação de abastecimento, uma vez que de acordo com Giatti et. al. (2004) essas enfermidades são conduzidas pela veiculação hídrica.

As formas específicas de armazenamento, conforme indicam as Figuras 03 e 04 se estruturam, sobretudo, através dos riscos provenientes do acumulo de água. De acordo com Ferreira e Silveira (2004) e d'Aguila et al., (2000) diversos vírus podem se desenvolver no contexto de água parada, inclusive vetores de doenças. Nesta perspectiva, destaca-se a dengue (Tabela 01), que no caso particular de Massaranduba, está associada ao acumulo de água principalmente em toneis (Figura 03). 


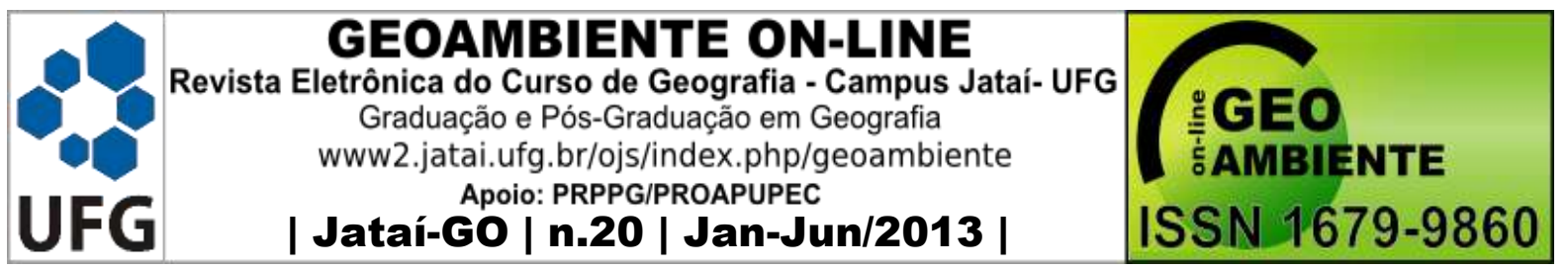

Figura 03: Modelo explicativo das formas de armazenamento e abastecimento no município de Massaranduba - PB

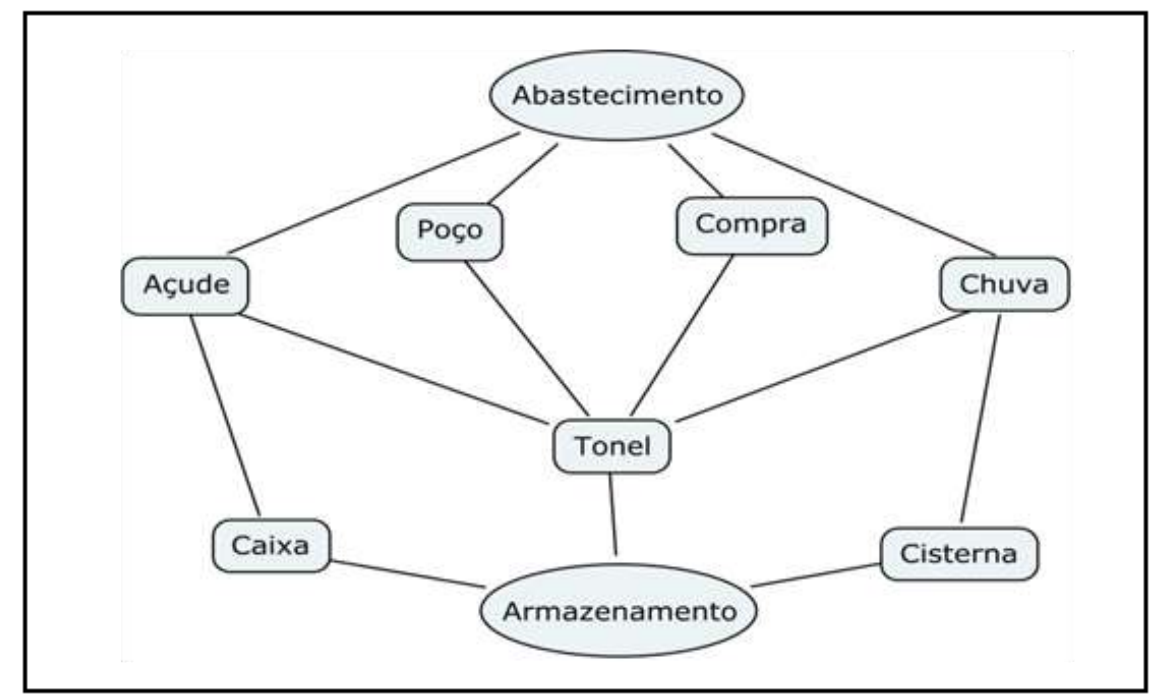

Fonte: Trabalho de Campo. Massaranduba - PB Agosto de 2012. Organizado por Silva Filho, 2012.

Assim, as discussões a respeito de determinantes e condicionantes socioambientais na fomentação das condições de saúde, em especial nas condições de abastecimento e armazenamento de água, viabilizam alternativas multidisciplinares que consideram tanto os vieses quantitativos, quanto a percepção dos cidadãos que vivenciam e interferem no espaço geográfico em suas dimensões materiais e imateriais que resultam, e ao mesmo tempo são resultados das condições gerais de existência.

\section{Conclusões}

- As implicações epidemiológicas decorrentes das condições de consumo da água são potencializadas por implicações condizentes ao armazenamento e as diferentes alternativas de abastecimento;

- As condições ambientais de disponibilidade de água e a configuração social das condições de abastecimento e armazenamento assumem influências no contexto epidemiológico vivenciado;

- As doenças são deflagradas pela baixa qualidade do abastecimento público, bem como seu acondicionamento indevido. 


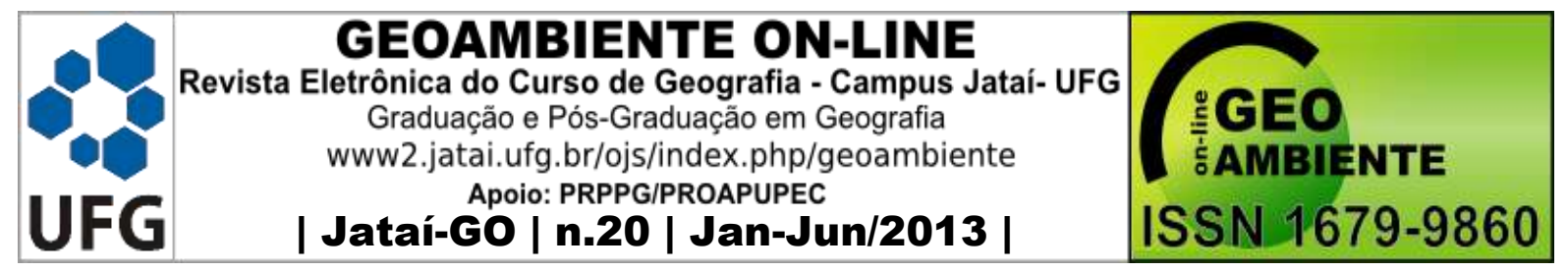

\section{Referências}

AESA. Monitoramento e qualidade da água. Agência Executiva de gestão das águas no estado da Paraíba, dados referentes aos reservatórios monitorados no estado, fornecidos em meio eletrônico. 2012.

ANA. Redes de abastecimento de água na microrregião de Campina Grande. Dados referentes às redes de abastecimento na microrregião de Campina Grande, fornecidos em meio eletrônico. 2012.

AMARAL, L. A.; NADER FILHO, A. ROSSI JUNIOR, O. D.; FERREIRA, F. L. A.; BARROS, L. S. S. Água de consumo humano como fator de risco a saúde em propriedades rurais. Rev. Saúde Pública. São Paulo. 37(4) 510-514. 2003.

BARCELLOS, C. PUSTAI A. K. WEBER, M. A. Identificação de locais com potencial de transmissão de dengue em Porto Alegre através de técnicas de Geoprocessamento. Revista da sociedade brasileira de medicina tropical (38)3. 246-250.2005.

d'AGUILA, P. S.; ROQUE, O. C. C.; MIRANDA, C. A. S; FERREIRA, A. P. Avaliação da qualidade de água para abastecimento público do município de Nova Iguaçu. Cad. Saúde Pública. Rio de Janeiro. 16(3). 791-798. 2000.

EVANS, N. A. Gym and tonic: a profile of 100 male steroid users. Br. J. sports med., Loughborouhh,. 31. 54-58. 1997.

FERREIRA, C. T. SILVEIRA, T. R. Hepatites virais: aspectos da epidemiologia e da prevenção. Rev. bras. Epidemiologia. 7(4). 437-487. 2004.

FERREIRA, E. P. de B.; DUSI, A. N.; XAVIER, G. R. ; RUMJANEK, N. G. Rhizosphere bacterial communities of patato cultivars evaluated through PCR-DGGE profiles. Pesquisa agropecuaria brasileira. 43. 605-6012. 2008.

FREITAS, M. B,; Brilhante, O. M.; ALMEIDA, L. M. Importância da análise de água para a saúde pública em duas regiões do Estado do Rio de Janeiro: enfoque para coliformes fecais, nitrato e alumínio. Cad. Saúde Pública. 17(3). 651-660. 2001.

IBGE. Censo Demográfico de 2010. Fundação Instituto Brasileiro de Geografia e Estatística, dados referentes ao município de Campina Grande, fornecidos em meio eletrônico. 2010.

MINAYO, Maria Cecília de Souza. O desafio do conhecimento: pesquisa qualitativa em saúde. 5. ed. São Paulo/ Rio de Janeiro: HUCITEC/ ABRASCO. 254p. 1998. 


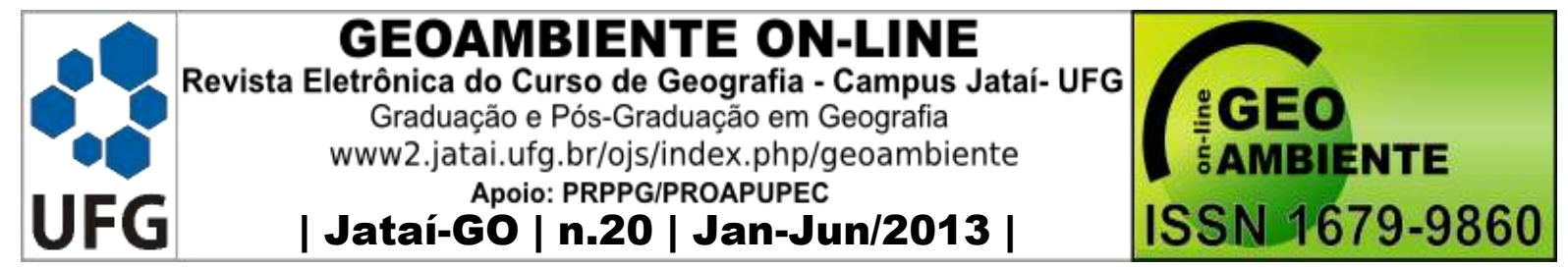

NERE, J. J. M. Uso de geotecnologia para comparação entre índice de doenças de veiculação hídricas e índice de condição material de vida na área urbana de Salinas - MG. Dissertação (Desenvolvimento regional e meio ambiente) Centro de desenvolvimento regional, Universidade Estadual de Santa Cruz - Ilhéus, BA. 72f.

PNAD - Pesquisa Nacional por Amostra de Domicílio (PNAD). Relatório detalhado sobre o estudo. 2004. 